\title{
Qualitative Assessment of the Pharmacist's Role in Punjab, Pakistan: Medical Practitioners' Views
}

\author{
Saira Azhar ${ }^{1 *}$, Mohammad Azmi Hassali ${ }^{2}$, Ayesha Iqbal ${ }^{1}$, Muhammad Rouf \\ Akram $^{3}$, Mufti Attique-Ur-Rehman ${ }^{3}$, Sabiha Karim ${ }^{4}$, Imran Tariq ${ }^{4}$, Muhammad \\ Hassham Hassan Bin Asad ${ }^{1}$, Ismail Tarjik ${ }^{5}$ and Ghulam Murtaza ${ }^{1}$ \\ ${ }^{1}$ Department of Pharmacy, COMSATS Institute of Information Technology, Abbottabad, Pakistan, ${ }^{2}$ Discipline of Social and \\ Administrative Pharmacy, University Sains Malaysia, Penang, Malaysia, ${ }^{3}$ Department of Pharmacy, University of Sargodha, \\ Sargodha, ${ }^{4}$ University College of Pharmacy, University of Punjab, Lahore, ${ }^{5}$ Department of Pharmacy, University of Peshawar, \\ Peshawar, Pakistan
}

*For correspondence: Email: drsairaazhar@gmail.com; Tel: 00923142082826; Fax: 0092992383441

\begin{abstract}
Purpose: To assess the perception of Pakistani doctors regarding pharmacist's role in Punjab Pakistan. Methods: A qualitative approach was used to assess the perception of doctors regarding pharmacist's role in the study setting. A total of 12 doctors were interviewed using a semi- structured interview guide. The study was conducted for a period of 3 months in the Pakistani cities of Islamabad and Lahore, from July to September 2011. Doctors were informed regarding the aim, objective and nature of the study. Results: All the interviews were transcribed verbatim and thematically analyzed for their content. Thematic content analysis yielded four major themes: 1) Availability of pharmacist in Pakistan's healthcare setting. 2) Willingness to collaborate with pharmacist. 3) Separation of prescribing from dispensing. 4) Difference in academic levels of doctors and pharmacist.

Conclusion: Doctors are receptive to an expanded role for pharmacists, also regard them as drug information experts, but their expectations fall short of the quality of clinically-focused pharmacy services that pharmacists are actually rendering.
\end{abstract}

Keywords: Doctors' expectation, Pharmacist, Clinical pharmacy services, Qualitative study, Prescribing

Tropical Journal of Pharmaceutical Research is indexed by Science Citation Index (SciSearch), Scopus, International Pharmaceutical Abstract, Chemical Abstracts, Embase, Index Copernicus, EBSCO, African Index Medicus, JournalSeek, Journal Citation Reports/Science Edition, Directory of Open Access Journals (DOAJ), African Journal Online, Bioline International, Open-J-Gate and Pharmacy Abstracts

\section{INTRODUCTION}

Hepler and Strand defined pharmaceutical care as the responsible provision of drug therapy for the purpose of achieving definite outcomes that improves the patient's quality of life by preventing and resolving drug related problems [1]. The concept of pharmaceutical care can only be achieved when the pharmacists and doctors both understand, appreciate each other's task and responsibilities different perceptions by the pharmacists and doctors concerning the pharmacist's role could reduce the quality of their collaboration cooperation [2].

Pharmacy practice has shifted its approach recently from product oriented to patient focused. Pharmacists are collaborating with patient, caregivers and other healthcare professionals more frequently and effectively than previously [3]. In US, studies conducted on physicians' expectation of pharmacists, regarding expanded pharmacists' role $[4,5]$. In these studies, the physician do support pharmacists' services but 
still a mix perception is seen regarding physicians' current and future expectations and current experiences with pharmacists [6]. Pharmacists' collaboration with physician was also studied in Kuwait. The outcomes of the study have shown that physicians in Kuwait felt comfortable with pharmacists providing a broad range of services, including direct patient care [7]. In Thailand, pharmacists in hospitals are playing an important role as part of the healthcare team and are promoting national drug use policy for the nation [8]. Furthermore, studies have shown that young physicians are more socialized to accept the inter-professional role of pharmacist.

The most common experiences of medical practitioners with pharmacists were reported to be the discouragement of patients through the provision of inappropriate drug information, dispensing of unauthorized refills, and making inappropriate decision in presence of the patients [10]. Therefore, perception of doctors regarding pharmacist's role is very crucial. To the best of our knowledge, this study is the first qualitative assessment by doctors regarding their perceived role of pharmacists and the frequency of interaction between pharmacists and doctors in Pakistan.

\section{METHODS}

Qualitative methodology was used to explore the perception of doctors towards pharmacists. An interview guide was developed after extensively reviewing the literature. On the basis of interview guide semi-structured interviews were used to collect the data. The participants were the doctors recruited through researcher's personal contacts from government hospitals of two cities of Pakistan, Islamabad and Lahore, from July to September 2011. Arrangements for the time and place of interviews were made during the initial contact. Written consents were obtained from the participants prior to the interview. The interviews mainly focused on doctors' perception on the role of pharmacists and their willingness to collaborate with pharmacists. Furthermore, information was gathered regarding their experience of working with pharmacists in their respective hospitals. Probing questions were used where necessary and the participants were given freedom to express their views at the end of the interview session. Each interview was conducted by the researcher at the place and time convenient for the doctors and lasted approximately twenty to thirty minutes. All the interviews were conducted in English, audio taped and transcribed verbatim. Transcripts were verified by the researcher for their accuracy by listening to the tapes. The researcher analyzed the transcripts line by line, which were read repeatedly by the expert and thematically analyzed for its content [11]. From the analysis, saturation of data was reached after 12 interviews with no new themes emerging in the last two interviews.

\section{RESULTS}

Twelve interviews were conducted. Among the participants seven were male while five were female. Demographic characteristics of respondents are shown in Table 1.

Table 1: Doctor's demographic data

\begin{tabular}{ll}
\hline Variable & $\mathrm{N}$ \\
\hline Age (years) & 3 \\
$\quad<30$ & 5 \\
$30-40$ & \\
$41-50$ & 7 \\
Gender & \\
$\quad$ Male & 5 \\
$\quad$ Female & \\
Pakistani institution attended & 5 \\
$\quad$ King Edward Medical College, Lahore & 2 \\
$\quad$ Fatima Jinnah Medical College, Lahore & 1 \\
$\quad$ Quaid-e-Azam Medical College, Bahawalpur & 1 \\
$\quad$ Nishtar Medical College, Multan & 3 \\
$\quad$ Foundation Medical College, Islamabad & 1 \\
Duration of practice in Pakistan & \\
$\quad>10$ years & 5 \\
$\quad<10$ years & 7 \\
\hline
\end{tabular}

Thematic content analysis yielded four major themes:

1) Availability of pharmacist in Pakistan's healthcare setting.

2) Willingness to collaborate with pharmacist.

3) Separation of prescribing from dispensing.

4) Difference in academic level of doctors and pharmacist.

\section{Theme 1: Availability of pharmacist in Pakistan's healthcare settings}

To investigate the availability of the pharmacists in hospitals, participants were asked about the pharmacists' presence in the hospitals. All informants were aware of their importance but their absence was notified.

"The pharmacists are very important persons for any health care system; in our health system, the pharmacists are present but only in papers, not physically." (D6) 
"Although presence of the pharmacist is very important in any health care setting, unluckily, we don't have any pharmacist in our health care setting. We are working without any pharmacist." (D9)

\section{Theme 2: Willingness to collaborate with pharmacists}

All the participants were agreed when they were asked about their willingness to collaborate with pharmacists.

"Yes, of course, I would like to work with them. The pharmacists help me for the care of my patients as sometimes there are so many drugs available, only a pharmacist can guide me which one is the most suitable drug therapy for the patients."(D1)

"Yes, I would like to work with the pharmacists. We want to have a good relationship with the pharmacists. I think we should work in the best interest of the field as well as for the patients and should collaborate with each other." (D5)

\section{Theme 3: Separation of prescribing from dispensing}

Separation of prescribing from dispensing is one of the major issues among developing countries. The participants expressed that there is no concept of dispensing separation in Pakistan.

\section{Not present in Pakistan's healthcare system}

"Ideally, I can give opinion if either of the situations is present and only then we can see the advantages and disadvantages of that situation. First of all, it should be practically implemented, then we will be able to comment. It is desperately needed but all we wanted is that it should be started in any form. It is not practically present."(D3)

"Here the doctor is the pharmacist; the doctors are prescriber, the doctor is retailer, the doctor is dispenser, the doctor is everything in most of the institutions in Pakistan; there is no concept of even that of the pharmacist; proscribing dispensing is very far."(D6)

\section{Issues pertaining to separation practice}

"I think the biggest problem is the finance; the salary is not good. Opportunity in the government is not enough for the pharmacists. All the segments are equally responsible for this, not only the government."(D6)
"In Pakistan, there is no proper job structure for the pharmacists; the government does not employ them on regular basis; whole of the burden is on the doctors. There should be jobs for the pharmacists; their appointment should be solely on every pharmacy so that proper collaboration should be done."(D8)

Theme 4: Difference in academic level of doctors and pharmacist

Some doctors pointed out the need of practical exposure of the pharmacists in the hospitals so that the collaboration of both the professions will help the patients' outcomes.

"Yes, there is a difference in academic level. The pharmacists think only about pharmacy, pharmacology and don't know about other basic medical subjects. Our collaboration with the pharmacists will help the patients' outcomes."(D8)

“The pharmacists don't have practical knowledge and exposure. They should work in the hospitals, only then they can know about the patients' diseases, the proper prescription of the drug and as to why the doctor is prescribing that drug. So, there is academic difference and the pharmacists should work more towards the clinical side."(D2)

\section{DISCUSSION}

Pharmacy practice has shifted its approach recently from product oriented to patient focused. Pharmacists are collaborating with patient, caregivers and other healthcare professionals more frequently and effectively than previously [3]. This results in the enhancement of the ability of pharmacists and physicians to work together resulting in improved patient care [12]. Studies in developed countries showed that physicians have accepted the extended role of pharmacists [13]. Findings suggest greatest potential for the expansion of pharmacists' role [14]. Moreover there are studies which have focused on the perception and collaboration of healthcare professionals regarding pharmacists in healthcare system [4,5]. In these studies, the physicians do support pharmacists' services but overall, physicians do not know what to expect of pharmacists. Most of the time with increased frequency of contact and collaboration with other individuals, comes the possibility of creating interpersonal conflict [6]. Few studies have shown negative experiences with the pharmacists. It was reported that some pharmacists have been involved in dispensing alternatives instead of prescribed medicines by 
the physicians [2]. In the context of developing countries, pharmacy practice varies significantly from one country to another. In the case of Pakistan, the pharmacy profession is at an early stage of development in terms of pharmaceutical care. During recent years, in most of the public sector hospitals, the number of pharmacists appointed was small and insufficient. Therefore, their role is limited to drug provision, procurement and inventory control. To understand the perception of Pakistani doctors regarding their recent experience of pharmacists and pharmacy services provided by them and their future expectation is very critical. It can be concluded that age may have effect on physician opinion of the pharmacist [9]. This will help to develop strategies for the better services provided to patients in future. Similar studies were conducted in the West [15]. Although the doctors in Pakistan's setting agreed that the pharmacists are the important members for any healthcare settings, but all the participants agreed on their non-availability in the hospitals, some of the doctors highlighted that there is practically no pharmacist in the hospitals. This severe shortage of pharmacists in Pakistan healthcare system was also highlighted before [16]. Pharmaceutical care is worldwide accepted as a mission of pharmacy, which cannot be fulfilled without the collaboration with other healthcare professionals to practice rational drug use [2]. This perception is mentioned by our informants and is consistent with Pakistani study conducted in 2009 [10], which reported that 47.2 $\%$ of the doctors strongly agreed to be assisted by the pharmacist in designing drug therapy treatment plans for the patients. Less than half of the respondents think that the pharmacists interact directly with the patients, this finding is in line with observation in different countries [17]. Moreover, on the other hand, it is also important that the pharmacists should better understand what the doctors expect from them and their perceptions to involve the pharmacists for the betterment of patient care. In many developed and developing countries, the separation of prescribing from dispensing is not common due to insufficient pharmacy coverage, increased drug accessibility and availability for their patients and for financial gain [18]. Healthcare situation in Pakistan is very critical, as participants expressed that there was no concept of prescribing/dispensing separation in the country, as the number of the pharmacists is less than what is required. The participants expressed that they were not happy with the present situation where the doctors hold the burden of healthcare alone. When the participants were asked about the issues regarding separation practice, they expressed that one of the common issues was lack of job opportunities for the pharmacists.

Lack of practical knowledge and exposure was perceived as one of the facts of difference in the academic level of doctors and pharmacists. To overcome these differences, some of the participants suggested that there should be revision of the curriculum, as it is most important to give greater exposure hospital pharmacists.

\section{Limitations of the study}

The results reported in the study are subject to several limitations. This study was conducted among government hospital doctors from two cities of Punjab Province only. The exclusion of doctors from other provinces and other sectors would limit the generalizability of this study.

\section{CONCLUSION}

Doctors in the Pakistani cities covered in this study are receptive to an expanded role for pharmacists and also regard them as drug information experts. However, their expectations fall short of their actual experience of pharmacists with regard to provision of quality clinically-focused pharmacy services. They also appear somewhat less comfortable with pharmacists providing direct patient care. The doctors experience a shortage of practicing pharmacists in hospitals.

\section{REFERENCES}

1. Hepler $C D$, Strand $L M$. Opportunities and responsibilities in pharmaceutical care. Am J Hosp Pharm 1990; 47: 533-543.

2. Paul L, Ranelli, June B. Physicians' perceptions of communication with and responsibilities of pharmacists. J Am Pharm Assoc 2000; 40(5): 1-7.

3. Louis MM, Schommer JC, Finnegan JR. Construct identification and measure development for investigating pharmacist-patient relationships. Patient Educ Counsel 2003; 51: 229-238.

4. George RB, Romeo B. New York state primary care physicians' attitude to community pharmacists' clinical services. Arch Intern Med 1996; 156(13): 91-94.

5. Smith WE, Ray MD, Shannon DM. Physicians' expectations of pharmacists. Am J Health System Pharm 2002; 59(1): 50-57.

6. Zubin A, Paul G, Caring MJ. Pharmacists' experience of conflict in community practice. Res Soc Admin Pharm 2010; 6: 39-48.

7. Matowe L, Abahussain EA, Al-Saffar N, Bihzad SM, AlForaih A. Physicians' perception and expectations of pharmacists' professional duties in government 
hospital in Kuwait. Med Princ Prac 2006; 15(6): $185-$ 189.

8. Maneerat RL, Wanapa S, Supatra C, Albert IW. Sources of information for new drugs among physicians in Thailand. Pharm World Sci 2007; 29: 619-627.

9. Grussing PG, Goff DA, Kraus DM, Mueller CE. Development and validation of an instrument to measure physician attitudes towards the clinical pharmacists' role. Drug Intelligen Clin Pharm 1984; 18(7): 635-640.

10. Azhar S, Hassali MA, Ibrahim MIM. Doctors' perception and expectations towards the role of pharmacist in Pakistan's healthcare system. Trop J Pharm Res 2010; 17: 192-199.

11. Creswell WJ, Michael DF, Nataliya VL. Designing a mixed methods study in primary care. Annal Family Med 2004; 2: 7-12.

12. McDonough RP, Doucette WR. Developing collaborative working relationships between pharmacists and physicians. J Am Pharm Assoc 2000; 41(5): 682-692.

13. Edmundsa J, Calnanb MW. The reprofessionalisaton of community pharmacy? An exploration of attitude to extended role for community pharmacists and general practitioners in the United Kingdom. Soc Sci Med 2001; 53: 943-955.

14. Rachel J, Graham J, Sewell. Risks and concerns about supplementary prescribing: survey of primary and secondary care pharmacists. Pharm World \& Sci 2006; 28: 76-90.

15. Ferris J, Marilyn R. Physicians' Opinions of Expanded Clinical Pharmacy Services. Am J Public Health 1983; 73(1): 318-322.

16. Azhar S, Hassali MA, Mohamed Ibrahim MI, Ahmad M, Masood I, Shafie AA. The role of pharmacists in developing countries: the current scenario in Pakistan. Human Res Health 2009; 7(1): 54-59.

17. Awad A, Matowe L, Capps P. Medical doctors perceptions and expectations of the role of hospital pharmacist in Sudan. Pharm World Sci 2007; 29: 557-564.

18. Lima D, Emeryc J, Lewisa J, Sunderlandd VB. A systematic review of the literature comparing the practices of dispensing and non-dispensing doctors. Health Policy 2009; 92: 1-9. 